\title{
Non-anatomic lung resection by video-assisted thoracoscopic surgery
}

\author{
Renata Baú, Spencer Marcantonio Camargo, Stephan Adamour Soder, José Carlos Felicetti \\ Pavilhão Pereira Filho, Irmandade Santa Casa de Misericórdia de Porto Alegre, Porto Alegre, Brazil \\ Contributions: (I) Conception and design: All authors; (II) Administrative support: All authors; (III) Provision of study materials or patients: All \\ authors; (IV) Collection and assembly of data: All authors; (V) Data analysis and interpretation: All authors; (VI) Manuscript writing: All authors; (VII) \\ Final approval of manuscript: All authors. \\ Correspondence to: Spencer Camargo. Thoracic Surgery and Lung Transplantation Unit, Pavilhão Pereira Filho, Dom Vicente Scherer Hospital, \\ Irmandade Santa Casa de Misericórdia, Porto Alegre, Brazil. Email: smcamargo@terra.com.br.
}

\begin{abstract}
Most of the patients with pulmonary neoplasia are diagnosed at an advanced stage in Brazil. Consequently, the possibility of curative surgical treatment is restricted to less than $30 \%$ of patients with surgical indication. The difficulty of including a greater number of these individuals is in the difficulty of an early diagnosis of the disease, leading it to more advanced stages. Currently, despite the lack of statistical studies, a project is underway to recruit patients to set up a lung cancer screening program in Brazil. In other words, early stages amenable to surgical treatment. The prevalence of lung cancer has also been increasing in Brazil and tuberculosis has once again become a public health problem. The World Health Organization (WHO) estimates that 9.6 million cases of tuberculosis occurred in 2014 . Out of this total, over $80 \%$ of the cases are concentrated in 22 countries, and Brazil ranks 19th in this classification. We also have to consider the possibility of the incidence of fungal diseases in a tropical country. With such disease profile, the presence of granulomas is high and differential diagnosis implies biopsies. In this context, small pulmonary nodules could be included in the surgical treatment for a differential diagnosis, or even for definitive treatment in certain patients with limitation for major surgeries, as in the case of lung cancer. For this group of patients, segmental, non-anatomic lung resection (wegde resection) could be performed with adequate results.
\end{abstract}

Keywords: Lung neoplasms; thoracic surgery; tuberculosis

Received: 03 August 2018; Accepted: 09 October 2018; Published: 04 December 2018.

doi: 10.21037 /jovs.2018.10.21

View this article at: http://dx.doi.org/10.21037/jovs.2018.10.21

\section{Introduction}

Following the evolution of radiologic techniques for chest imaging, such as high-resolution computed tomography, along with lung cancer screening programs, the number of early-stage cancer diagnoses has increased. Not only has the earlier diagnosis of small pulmonary nodules become routine, but also the occasional finding of ground glass lesions, which had a significant increase in the number of diagnoses, has become a new reality. For diagnostic elucidation, we often need to have these lesions biopsied to provide patients with definitive diagnosis and treatment $(1,2)$.

In Brazil, most of the patients with lung cancer are diagnosed at an advanced stage, which leads to the possibility of curative surgical treatment for only about $30 \%$ of this population. This fact is mainly due to delay in the diagnosis of cancer; at that time, most patients are diagnosed with an advanced tumor (3). Currently, despite the lack of statistical studies discussing the reality of cancer, a project is underway to recruit patients to install a lung cancer screening in a major center in Brazil (4).

In addition to the high prevalence of lung cancer in Brazil, the incidence of tuberculosis, which is still considered a public health problem, is high. According to the World Health Organization (WHO), there were about 9.6 million occurrences of the disease in 2014 worldwide. 
Out of this total, $80 \%$ of the cases are concentrated in 22 countries, Brazil ranking 19th in this classification. The number of cases of tuberculosis, which is manifested through a pulmonary nodule, the granuloma, is very high, often indicating nodule puncture or biopsy by nonanatomic segmentectomy (5).

The treatment of lung cancer presently allows us to discuss the type of pulmonary resection according to the nature of the lesion, size, and patient characteristics. Some studies suggest the benefit of limited lung resection techniques because they present favorable outcomes when compared to pulmonary lobectomy (6). This article aims to review the available literature on wedge resection in Brazil, as well as to shed light on the results of the thoracic surgery service at Santa Casa de Porto Alegre, a reference center in lung cancer treatment.

\section{Wedge resection}

Nowadays, thoracic surgeons are facing a new reality. The routine utilization of minimally invasive techniques to perform lung resections, the development of lung cancer screening programs, and the better understanding of natural history and meaning of ground-glass lesions with solid components have led to an increase in the number of patients visiting thoracic surgeon with pulmonary nodules.

In the last few years, the diagnostic of ground-glass pulmonary nodules has increased and the correlation between radiologic and histopathologic aspects is more recognized (2). Moreover, several retrospective and propensity-matched studies have shown similar 5-year disease-free and overall survival in the treatment of T1aN0M0 nodules by sublobar resection compared to lobectomy. Actually, two clinical trials are running to compare these methods to answer this controversial issue. When the surgeon is planning the resection, several characteristics of the patient and the nodule need to be evaluated to decide the modality of lung resection to be performed. The size, density, and localization of the nodule in the lobe with relation to the hilum, the distance to the intersegmental plane, as well as the cardiovascular and respiratory functions and patient performance status need to be carefully assessed $(6,9)$.

In solid nodules bigger than $2 \mathrm{~cm}$, curative-intent lobectomy is the chosen procedure. In the opposite scenario, nodules smaller than $2 \mathrm{~cm}$, especially the groundglass and peripheral lesions, seem to be adequately treated by sublobar resections without compromising oncologic outcomes, as satisfactory systemic staging and mediastinal lymph node sampling. The wedge resection is presented as a sublobar resection dispensing the hilum dissection, still searching for adequate circumferential margins. When the nodule is located in the middle or in the inner third of the lobe, wedge resection is more challenging. In such cases, the anatomic segmentectomy or even the lobectomy may be necessary to not compromise the parenchyma, vascular supply or deeper margins $(7,8)$.

Results from an important study published by The Lung Cancer Study Group (LCSG) comparing limited resection with pulmonary lobectomy to clinical stage IA showed that overall survival was lower in the limited resection group, in addition to a higher recurrence rate in that group. For many years, the results of such study made lobectomy indication unquestionable even in the early stages. However, some selection criteria in the patients studied in this trial give scope for a new discussion about patients' ideas for limited resection: while selecting the group of patients who underwent limited resection, were included central tumors $>2 \mathrm{~cm}$, central, and the surgical technique did not include lymph node resection (7).

Currently, there are two large ongoing trials Alliance/ CALGB 140503 and JCOG0802/WJOG4607 that compare the lobectomy $\mathrm{X}$ segmentectomy in patients with peripheral nodules smaller than $2 \mathrm{~cm}$ and without an invasive component $(7,8)$. Survival analysis will be the primary endpoint. While awaiting results, current prospective studies suggest that sublobar resection can be considered for appropriately-selected patients, with peripheral tumors (smaller than $2 \mathrm{~cm}$ ), and with adequate margin resection, and represent an excellent choice in patients above 75 years with frosted glass nodules (6,9-12)

Prospective studies comparing lobectomy with wedge resection were performed taking into account database and survival comparison among patients. Such studies show a tendency to choose wedge resection for patients with stage I non-small cell lung neoplasia, which is justified by the lower rate of postoperative complications in limited resection, in addition to greater preservation of lung function. However, such studies do not consider or usually lack data on the inclusion criteria of patients selected for limited resection (wegde or anatomic segmentectomy), which may directly influence the outcome, since these patients may have been selected to undergo the limited resection due to reduced pulmonary reserve to withstand major resection $(6,9)$.

A recently published systematic review comparing studies presenting survival rates in sublobar resection 
versus segmentectomy reinforces this discussion: patients who were intentionally selected had a similar outcome in the lobectomy and minor resection groups, and patients who only tolerated minor resection, either because of low cardiopulmonary reserve or because of the high risk due to their comorbidities, presented a worse outcome. This study reinforces that minor resection is a good alternative for partially solid and peripheral nodules smaller than $2 \mathrm{~cm}$ (13).

To date, the results available in the literature on the comparison between the two techniques (lobectomy, anatomical segmentectomy, and wedge resection) are mainly based on retrospective studies, and so far there have been no randomized trials which could allow us to affirm the superiority of a technique over another, eliminating selection biases.

\section{Cancer in Brazil}

The health system in Brazil is divided into public and private (73\% and $27 \%$ respectively) (14). Video-assisted thoracoscopic surgery (VATS) pulmonary resection surgery to date is only performed in patients who belong to the private system, as the public system does not cover the materials required for video-surgery.

Due to several factors, but mainly due to the delay in diagnosis, the minority of patients diagnosed with lung cancer in Brazil undergoes surgical treatment $(3,15)$. The high rate of late-stage diagnoses, the low frequency of patients receiving curative-intent treatment, and the large number of patients who are uncovered from medical care are some of the causes for the significant delay and inefficiency, from diagnosis to the beginning of treatment $(3,15,16)$.

The latest world estimate showed 596,000 new cases of cancer in Brazil in 2016, with 28,220 (4.7\%) cases of primary malignant neoplasm of the lung. In $90 \%$ of the diagnosed cases, lung cancer is associated with the consumption of tobacco derivatives. According to data from the INCA (National Institute of Cancer), lung cancer in Brazil accounted for 22,424 deaths in 2011. Lung cancer is a highly lethal disease: total cumulative mean survival over 5 years varies between $13 \%$ and $21 \%$ in developed countries and between $7 \%$ and $10 \%$ in developing countries. It is also estimated that there will be 31,270 new cases in 2018, 18,740 being men and 12,530 women (17).

Statistical data on diagnosis, treatment, and outcome of patients with lung cancer is scarce. Nevertheless, through the available literature we know that, as in developed countries, non-small cell lung cancer in Brazil is usually diagnosed in advanced stages and presents low survival rates. In approximately $70 \%$ of patients, the disease is locally advanced or metastatic at the time of diagnosis (18-21).

The high proportion of patients diagnosed at advanced stages raises interest in the need to prioritize primary disease prevention measures (such as tobacco control campaigns) as well as new strategies for early diagnosis (3). As screening programs become more consistent in public health in Brazil, the standardization of less invasive techniques for the diagnosis of pulmonary nodules gains space.

\section{Experience in southern brazil-at porto alegre/ rio grande do sul: pavilhão pereira filho, santa casa de misericórdia de porto alegre}

Our experience with VATS began in 2010 leading to a publication of our results in 2017, in which 117 anatomical pulmonary resections were analyzed (22). From January 2016 to December 2017, methylene-blue dye was injected for preoperative nodule localization in 61 patients $(67 \%$ were female; median age 66-year-old). Sixty-four nodules were removed and a malign neoplasia was diagnosed in 48 patients (78.9\%), with 41 primary lung adenocarcinomas, 01 epidermoid carcinoma, 01 carcinoid tumor and 05 nodules of metastatic origin. In all cases, the mediastinal lymph nodes were assessed and free margins were achieved.

Another current study (between 2010 and 2017) analyzed 1,603 minor resections. Out of those, 531 were wedge resection of which 332 were performed by VATS. As for video-surgeries, $44.5 \%$ of the cases were from benign lesions and $55.4 \%$ from malignant lesions: 98 adenocarcinomas, 12 epidermoid tumors, 1 pulmonary nodule with small cell postoperative diagnosis, 8 carcinoid tumors, 1 pulmonary lymphoma, and 64 metastasectomy.

The benign resections were motivated by bleebs for recurrent pneumothorax surgery, diagnosis of granulomatous and infectious diseases such as usual interstitial pneumonia, hypersensitivity pneumonia, and there were some other findings, such as simple congenital cyst and round pneumonia. From all the patients operated, ten had suspected lung nodules for neoplasia, with a postoperative granuloma-compatible outcome.

The indication for wedge resection in these patients was made in solid or subsolid nodules smaller than $2 \mathrm{~cm}$, patients with advanced age and bordering pulmonary reserve (Table 1). There were no trans-operative losses 
Table 1 Recommendations according to our experience

Ground glass less than $2 \mathrm{~cm}$

Patients with borderline pulmonary reserve

Diagnosis of nodules larger than $6 \mathrm{~mm}$

Metastasectomy

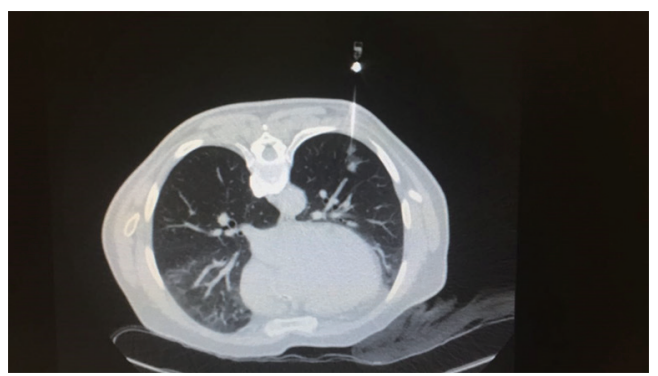

Figure 1 Blue methylene injection.

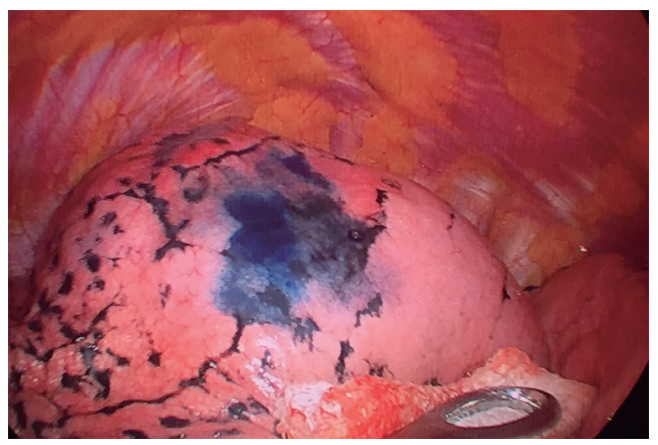

Figure 2 Intraoperative view of the area marked with blue.

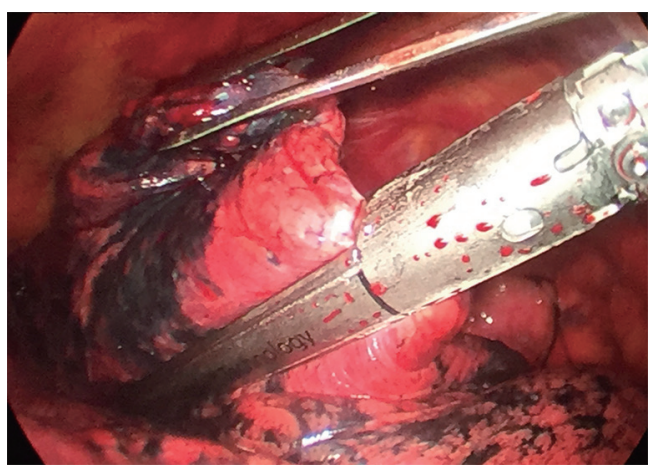

Figure 3 Intraoperative resection of the area marked with blue. in this period, and the most frequent complications were persistent wound leakage.

When dealing with mixed nodules with solid or pure solid lesions (smaller than 6 or $7 \mathrm{~mm}$ ), especially when they are not in a subpleural localization, they can be difficult or even impossible to be safely identified during the operation. In those cases, pre-operative planning is crucial, and a nodule localization method is frequently necessary to increase the complete resection rate and minimize excessive and unnecessary parenchyma loss. Several methods are described and utilized, including their advantages and disadvantages. At our institution, we have tested many of them: hook-wire, microcoil, technetium and barium injection. The barium can be spread by the parenchyma and not reabsorbed. Even after the resection, barium residual always is shown in chest images which could be psychologically disturbing for the patient. In the last few years, we have routinized the methylene blue injection immediately before the surgical procedure to localize the nodule. The radiologist learning curve is essential to improve the precision of the injection and minimizing the pleural dye spreading.

In patients undergoing blue methylene injection, the patient was placed in ventral decubit position or lateral, depends on the localization of the node, and a chest computadorized tomography is performed. The node is localized and the radiologist inject 5 to $10 \mathrm{~mL}$ of methylene blue (Figure 1). After that, the patient is transferred to the surgical room. In patients undergoing wedge resection segmentectomy (wedge), the following steps were taken: the patient was placed in lateral decubitus position. Seventh intercostal space puncture for 10-mm and 30-degree optic passage, and lateral mini-thoracotomy in fifth intercostal space, $4 \mathrm{~cm}$ high. The marked zones are localized and removed by stapler (Figure 2,3) All patients in the postoperative recovery were left with a chest drain, and intensive care unit (ICU)'s routine recovery is performed. For all patients, a safety margin of $2 \mathrm{~cm}$ from the lesion was observed.

\section{Conclusions}

The likelihood of a pulmonary response and at the same time therapeutics, with the obtaining of the imaging technique, are radiological for this, provided by VATS, in minimally invasive surgeries. The wedge resection is useful in the indication of resection of malignant or suspected malignant pulmonary nodules smaller than $2 \mathrm{~cm}$ in patients 
with borderline pulmonary reserve or who cannot tolerate a major resection. In addition, it is particularly useful to treat lung metastases, when the parenchyma can be spared considering the risk of new lung lesions development and the possibility of smaller margins. We look forward to having the results of the randomized studies in progress so that we can definitively unravel the differences in the outcomes of patients undergoing non-anatomic pulmonary resection and draw more definitive conclusions. We believe in the benefits of wedge resection mainly concerning the need for diagnosis, especially in countries with a high prevalence of granulomatous diseases, such as tuberculosis, as well as elderly patients with low pulmonary reserve, ground glass lesions requiring a diagnosis of up to 2 centimeters, individualizing each case.

\section{Acknowledgments}

Funding: None.

\section{Footnote}

Provenance and Peer Review: This article was commissioned by the Guest Editors (Ricardo M. Terra and Paula A. Ugalde) for the series "Minimally Invasive Surgery Robotics and VATS in Brazil" published in Fournal of Visualized Surgery. The article has undergone external peer review.

Conflicts of Interest: All authors have completed the ICMJE uniform disclosure form (available at http://dx.doi. org/10.21037/jovs.2018.10.21). The series "Minimally Invasive Surgery - Robotics and VATS in Brazil" was commissioned by the editorial office without any funding or sponsorship. The authors have no other conflicts of interest to declare.

Ethical Statement: The authors are accountable for all aspects of the work in ensuring that questions related to the accuracy or integrity of any part of the work are appropriately investigated and resolved.

Open Access Statement: This is an Open Access article distributed in accordance with the Creative Commons Attribution-NonCommercial-NoDerivs 4.0 International License (CC BY-NC-ND 4.0), which permits the noncommercial replication and distribution of the article with the strict proviso that no changes or edits are made and the original work is properly cited (including links to both the formal publication through the relevant DOI and the license). See: https://creativecommons.org/licenses/by-nc-nd/4.0/.

\section{References}

1. MacMahon H, Naidich DP, Goo JM, et al. Guidelines for Management of Incidental Pulmonary Nodules Detected on CT Images: From the Fleischner Society 2017. Radiology 2017;284:228-43.

2. Aberle DR, Berg CD, Black WC, et al. The National Lung Screening Trial: overview and study design. Radiology 2011;258:243-53.

3. Araujo LH, Baldotto C, Castro G Jr, et al. Lung cancer in Brazil. J Bras Pneumol 2018;44:55-64.

4. Santos RS, Franceschini J, Kay FU, et al. Low-dose CT screening for lung cancer in Brazil: a study protocol. J Bras Pneumol 2014;40:196-9.

5. Secretaria de Vigilância em Saúde. Departamento de Vigilância das Doenças Transmissíveis CoordenaçãoGeral do Programa Nacional de Controle da Tuberculose. Available online: http://portalarquivos2.saude.gov.br/ images/pdf/2016/outubro/15/panorama_tuberculose_ brasil_mortalidade.pdf

6. Kates M, Swanson S, Wisnivesky JP. Survival following lobectomy and limited resection for the treatment of stage I non-small cell lung cancer $<=1 \mathrm{~cm}$ in size: a review of SEER data. Chest 2011;139:491-6.

7. Nakamura K, Saji H, Nakajima R, et al. A phase III randomized trial of lobectomy versus limited resection for small-sized peripheral non-small cell lung cancer (JCOG0802/WJOG4607L). Jpn J Clin Oncol 2010;40:271-4.

8. Kohman LJ, Gu L, Altorki N, et al. Biopsy first: Lessons learned from Cancer and Leukemia Group B (CALGB) 140503. J Thorac Cardiovasc Surg 2017;153:1592-7.

9. De Waele M, Van Schil P. Limited resections in high-risk patients. Curr Opin Pulm Med 2015;21:309-13.

10. Smith CB, Swanson SJ, Mhango G, et al. Survival after segmentectomy and wedge resection in stage I non-smallcell lung cancer. J Thorac Oncol 2013;8:73-8.

11. Yano M, Yoshida J, Koike T, et al. Survival of 1737 lobectomy-tolerable patients who underwent limited resection for cStage IA non-small-cell lung cancer. Eur J Cardiothorac Surg 2015;47:135-42.

12. Yano M, Yoshida J, Koike T, et al. Survival of 1737 lobectomy-tolerable patients who underwent limited resection for cStage IA non-small-cell lung cancer. Eur J 
Cardiothorac Surg 2015;47:135-42.

13. Cao C, Chandrakumar D, Gupta S, et al. Could less be more?-A systematic review and meta-analysis of sublobar resections versus lobectomy for non-small cell lung cancer according to patient selection. Lung Cancer 2015;89:121-32.

14. Ministério do Planejamento, Orçamento e Gestão. Instituto Brasileiro de Geografia e Estatística (IBGE) [homepage on the Internet]. Rio de Janeiro: IBGE [acesso em 15/07/2018]. Pesquisa Nacional por Amostra de Domicílios 2008. Available online: http://www.ibge.gov.br

15. Câncer de pulmão: histologia, estádio, tratamento e sobrevida*. Available online: http://www.scielo.br/scielo. php?script=sci_arttext\&pid=S1806-37132008000800009

16. Sobrevida e fatores prognósticos em pacientes com câncer de pulmão de células não pequenas assistidos na saúde suplementar. Available online: http://www.scielo.br/pdf/ rbepid/v17n4/pt_1415-790X-rbepid-17-04-01001.pdf

17. Ministério da Saúde. Instituto Nacional de Câncer José Alencar Gomes da Silva (INCA) [homepage on the Internet]. Rio de Janeiro: INCA; Estimativa 2016: Incidência de Câncer no Brasil; 2015. Available online: http/inca.gov.br. [acesso em 01/07.2018].

doi: 10.21037/jovs.2018.10.21

Cite this article as: Baú R, Camargo SM, Soder SA, Felicetti JC. Non-anatomic lung resection by video-assisted thoracoscopic surgery. J Vis Surg 2018;4:242.
18. Secretaria de Estado da Saúde de São Paulo. Fundação Oncocentro de São Paulo [homepage on the Internet]. Acesso ao TABNET. Available online: http://fosp.saude. sp.gov.br/publicacoes/tabnet

19. National Cancer Institute. Surveillance, Epidemiology, and End Results Program (SEER) [homepage on the Internet]. Bethesda: National Cancer Institute; Câncer Stat Facts: Lung and Bronchus Cancer. Available online: http://seer. cancer.gov/statfacts/html/lungb.html

20. Cancer Research UK [homepage on the Internet]. London: Cancer Research UK; Lung Cancer Statistics. Available online: http://cancerresearchuk.org/healthprofessional/cancer-statistics/statistics-by-cancer-type/ lung-cancer

21. de Sá VK, Coelho JC, Capelozzi VL, et al. Lung cancer in Brazil: epidemiology and treatment challenges. Lung Cancer (Auckl) 2016;7:141-8.

22. Soder SA, Barth F, Perin FA, et al. Anatomic pulmonary resection via video-assisted thoracic surgery: analysis of 117 cases at a referral center in Brazil. J Bras Pneumol 2017;43:129-33. 